\title{
Análise da paisagem com o uso de geotecnologias: uma proposta metodológica para o planejamento territorial da região hidrográfica VIII - RJ
}

\author{
Landscape analysis with use of geotechnologies: a methodological proposal for territorial \\ planning the hydrographic region VIII - RJ \\ BARROS JUNIOR ${ }^{1}$, W. W.; SILVA $^{2}$, J. A. F.; LUGON JUNIOR ${ }^{3}$, J.; MOREIRA ${ }^{4}$, M. A. C.; \\ SANTOS $^{5}$, L. F. U. \\ wilmarwjr@gmail.com, jasilva@if.edu.br
}

\section{Resumo}

As Geotecnologias são excelentes instrumentos para gestão ambiental pela sua capacidade de integração de ferramentas e técnicas de modelagem dos fenômenos ambientais. Tendo como base o conceito de Análise da Paisagem é possível reconhecer os potenciais e as fragilidades de uma determinada área geográfica. A Região Hidrográfica VIII (RH-VIII), área de atuação do Comitê das Bacias Hidrográficas dos Rios Macaé e das Ostras (CBH Macaé/Ostras), apresenta alto grau de degradação ambiental devido à ocupação intensiva de terras impróprias ao uso. A preocupação com a gestão ambiental da região se manifesta a nível nacional, pois além do abastecimento público suas águas suprem boa parte das necessidades das indústrias de petróleo instaladas na região. Os módulos de Análise de Múltiplos Critérios (AMC) dos Sistemas de Informações Geográficas (SIG) se apresentam como uma ferramenta viável em estudos de ordenamento territorial. Busca-se com a pesquisa fazer uma revisão da literatura visando adequar proposta metodológica para planejamento territorial da RH-VIII.

Palavras-chave: Ecologia de Paisagem. Gestão e Planejamento Territorial. Apoio à Tomada de Decisão.

\begin{abstract}
Geotechnology is presented as an excellent tool for environmental management due to its capacity of interaction and modeling techniques of environmental phenomena. Based on Landscape Analysis concept it is possible to recognize the potential and the weaknesses of a particular geographical area. The Hydrographic Region VIII (RH-VIII), where the Committee of Hydrographic Basins of Macaé and Ostras rivers (CBH Macaé/Ostras) operates, presents high levels of environmental degradation due its intensive occupation of improper areas for use. The concern of environmental management for the region is expressed in national level, due to the fact that besides the public supply, its water provides a good portion of the oil industries needs in the region. The modules of Multi-Criteria Analysis (MCA) of Geographic Information Systems (GIS) are presented as a viable tool in territorial planning studies. So the aim is to make research a literature review in order to systematize the references related to the topic and propound a resource to elaborate a territorial planning of the RH-VIII.
\end{abstract}

Keywords: Landscape Ecology. Management and Territorial Planning. Support in Decision-Making.

\section{INTRODUÇÃ̃O}

A degradação do ambiente por ações antrópicas é um dos impactos ambientais de maior relevância e discussão dentro do atual contexto sociopolítico. Esse conceito pode ser entendido como perda de características naturais, destruição ou deterioração desgaste gerados ao meio

\footnotetext{
${ }^{I}$ Wilmar Wan-De-Rey De Barros Júnior, Mestrando em Engenharia Ambiental, Instituto Federal de Educação, Ciência e Tecnologia Fluminense, Macaé-RJ, Brasil.

${ }^{2}$ José Augusto Ferreira da Silva, Instituto Federal de Educação, Ciência e Tecnologia Fluminense, Macaé-RJ, Brasil.

${ }^{3}$ Jader Lugon Júnior, Instituto Federal de Educação, Ciência e Tecnologia Fluminense, Macaé-RJ, Brasil.

${ }^{4}$ Marcos Antônio Cruz Moreira, Instituto Federal de Educação, Ciência e Tecnologia Fluminense, Macaé-RJ, Brasil.

${ }^{5}$ Luís Felipe Umbelino dos Santos, Instituto Federal de Educação, Ciência e Tecnologia Fluminense, Macaé-RJ, Brasil.
} 
ambiente a partir do desenvolvimento de atividades econômicas e ou ocupação humana (PINTO et al., 2013). Desde então a busca por medidas mais racionais tem se tornando prioridade para a conservação dos ecossistemas.

Análise da Paisagem é um conceito bastante utilizando nas Geociências, a sua prática consiste em estudar os elementos presentes em uma unidade territorial delimitada por características geomorfológicas pré-determinadas. Nesse sentido a natureza não é observada somente pelos seus componentes, mas também as suas conexões e interações, nos permitindo compreender a sua dinâmica de transformação (BERTRAND, 2004; MUCHAILH, 2007).

As bacias hidrográficas são unidades territoriais com dimensões variadas e segundo Carvalho e Silva (2006) podem ser definidas como uma área que é delimitada unicamente por sua topografia onde sua drenagem é realizada por um curso d'água ou um sistema de cursos d'águas conectados de tal forma que toda sua vazão efluente é descarregada por uma única saída. No seu interior os recursos naturais e fenômenos se interagem, dessa forma proporcionando um ambiente constituído por subsistemas interativos e de fácil reconhecimento (CAZULA; MIRANDOLA, 2010).

Nessa lógica, a bacia hidrográfica é tomada como unidade básica de gestão e planejamento ambiental por diversos autores e profissionais. E para propósito de estudos em bacias hidrográficas deverão ser feitos levantamentos detalhados das informações ambientais, sociais e culturais assim como suas interações para uma melhor conclusão (PHILIPPI JUNIOR; SILVEIRA, 2004).

A Região Hidrográfica VIII (RH-VIII) está localizada no Litoral Norte do Estado do Rio de Janeiro, drenando uma área de $2.013 \mathrm{~km}^{2}$, pertencendo ao Bioma de Mata Atlântica onde se destaca o Corredor da Serra do Mar. O Rio Macaé é considerado um importante manancial a nível nacional, pois apesar do abastecimento público da região, seus recursos suprem as necessidades de boa parte das indústrias do petróleo da região, se tornando essencial para cadeia produtiva do combustível (CBH MACAÉ/OSTRAS, 2012a).

Os aspectos ambientais da RH-VIII se apresentam bastantes impactados devido à intervenção humana, com destaque ao represamento e retilinização dos cursos d'água, uso e ocupação de áreas restritas e a retirada da cobertura vegetal para atividade agrícola. Porém é demostrado que na bacia há importantes remanescentes de Mata Atlântica a serem preservados (CBH MACAÉ/OSTRAS, 2012a).

As Geotecnologias pode ser conceituada de um conjunto de técnicas e métodos científicos para coleta, processamento, análise e oferta de informações com referência geográfica. Essas técnicas podem ser aplicadas sobre diversas temáticas como em pesquisas dos recursos naturais, no estudo da paisagem, desastres naturais e nas atividades humanas (TÔSTO et al., 2014). Segundo 
Bolfe (2006) as Geotecnologias se tornam uma ferramenta fundamental para a gestão dos recursos naturais, pois permitem a otimização do tempo de análise para tomada de decisões, imprescindível para regiões distantes e de difícil acesso.

Dentro do universo das Geotecnologias podemos destacar o Sensoriamento Remoto, uma técnica capaz de capturar a energia eletromagnética refletida pelos objetos na terra para produção de informações dos recursos e fenômenos naturais, assim como os Sistemas de Informações Geográficas (SIG) uma tecnologia baseada em banco de dados gráficos e não gráficos que permite o processamento das informações para uma análise espacial (ROSA, 2005; LORENZZETTI, 2015).

A busca pela solução ideal para determinado problema é um conceito bastante discutido na sociedade atual, nessas circunstâncias verifica-se o desenvolvimento de ferramentas que dão apoio à tomada de decisões, dentre as quais podemos destacar a Análise por Múltiplos Critérios (AMC), que é utilizada para os problemas cujo apresentam um conjunto de soluções possíveis e com múltiplos objetivos (PARREIRAS, 2006). De acordo com Born (2013) diversas metodologias de AMC podem ser desenvolvidas em ambiente de SIG, gerando um produto que facilite a tomada de decisão de uso para um determinado espaço territorial de acordo com a sua aptidão, qual se destaca a técnica de Processo Analítico Hierárquico (PAH), onde os critérios são avaliados de acordo com a sua prioridade.

Alguns SIG incluem em seus módulos funcionais, ferramentas para auxílio à tomada de decisão para melhor alocação de recursos. Módulos que incorporam erros em processos e auxiliam na construção de mapas de pertinência em AMC. Esses módulos também endereçam alternativas quando existem múltiplos objetivos envolvidos, dessa forma dando apoio os gestores na tomada de decisão (SILVEIRA, 2004).

É importante destacar a atuação do Comitê de Bacia Hidrográfica dos Rios Macaé e das Ostras (CBH Macaé/Ostras) na RH-VIII, que durante a elaboração do Plano de Recursos Hídricos identificou a necessidade de realizar uma atividade voltada ao planejamento territorial de toda região (CBH MACAÉ/OSTRAS, 2012b).

Visando colaborar para um melhor ordenamento territorial e com a gestão das águas na RHVIII, buscou-se com a pesquisa uma revisão bibliográfica sobre os temas apresentados objetivando a propositura de técnicas capaz de identificar a aptidão quanto ao uso das terras, com a temática de desenvolvimento humano, conservação e preservação ambiental.

\section{ANÁLISE DA PAISAGEM COM O USO DE GEOTECNOLOGIAS}

O termo paisagem é utilizado em distintas atividades profissionais como Artes, o Turismo, a Arquitetura e a Biologia, dentre muitas outras, logo sua conceituação é polissêmica e está associada 
à perspectiva do observador (BERTRAND, 2004; METZGER et al., 2007). Evitando distorções, será adotado o conceito empregado no campo das Geociências, onde a paisagem se define como unidades ecológicas compostas por mosaicos de ecossistemas que interagem em uma área ampla delimitada por características geomorfológicas e com regime específico de alterações, a sua formação é fruto da interação dos componentes geológicos, expostos à ação do clima, fatores geomorfológicos e bióticos que, através do tempo, refletem atualmente os registros acumulados da evolução biofísica. Este conceito é também vastamente utilizado por diversos profissionais que estudam as questões vinculadas à gestão ambiental ou ao planejamento territorial em seus diversos níveis, escalas e recortes temáticos de análise (MUCHAILH, 2007; DANTAS et al., 2015).

A paisagem apresenta uma dinâmica de transformação relacionada à ação humana no espaço geográfico. Atualmente o modo de desenvolvimento da sociedade faz com que essa atividade se torna cada vez mais presente e intensa nos ambientes. Dessa forma, não se pode mais divulgar a existência de paisagens naturais, pois todas apresentam ao menos uma forma de interferência antropogênica podendo ser em maior ou menor grau de intervenção. Nesse contexto a paisagem não é simplesmente o conjunto de fatores geomorfológicos associados a elementos bióticos em um ambiente demarcado, e sim o resultado da combinação dinâmica, portanto instável, de elementos físicos, biológicos e antrópicos que, reagindo aleatoriamente uns sobre os outros, fazem da paisagem um conjunto único e inseparável que está em perpétua evolução, em uma determinada porção do espaço. (BERTRAND, 2004; DANTAS et al., 2015).

A discursão anterior é fundamental para compreensão da teoria geossistêmica, sistematizado na Figura 1, onde a definição é baseada na interconexão de fluxos de matéria e energia entre os elementos bióticos, abióticos e antrópicos, cujo o resultado sustenta a formação de uma dimensão no espaço terrestre (BERTRAND, 2004).

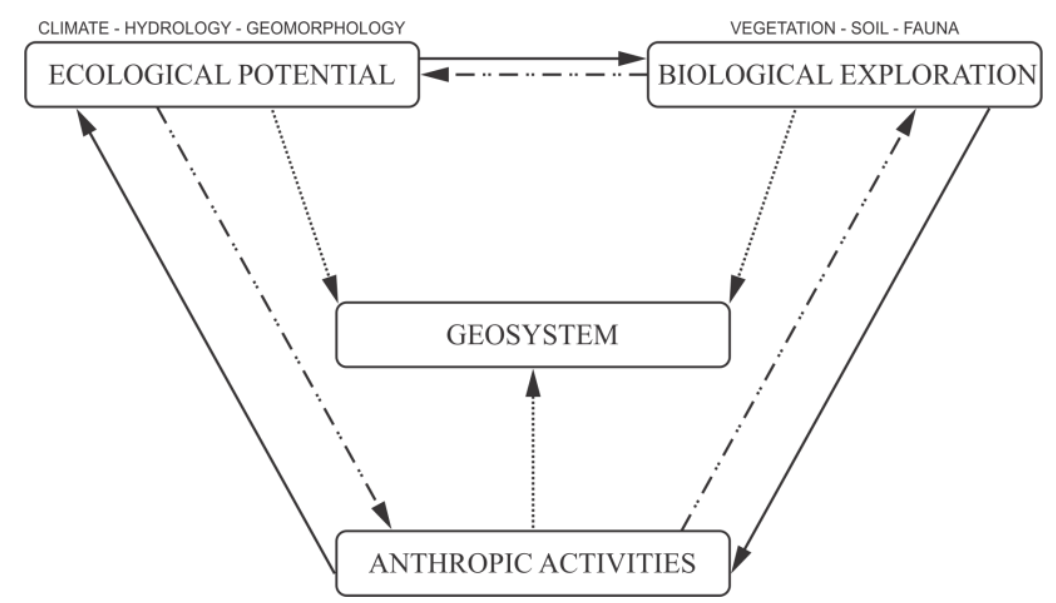

Figura 1 - Esboço de uma definição teórica de geossistema. Fonte: Bertrand (2004). 
O estudo da paisagem, na perspectiva da interação dos elementos para uma abordagem sistêmica, favorece o reconhecimento das estruturas vertical e horizontal da paisagem, bem como sua dinâmica evolutiva (ESTÊVEZ et al., 2011). A estrutura horizontal é a base para a ecologia da paisagem. E o reconhecimento que as interações entre as unidades de paisagem podem interferir no funcionamento das unidades relacionadas, admitindo a dependência espacial entre as unidades de paisagem, o seu estudo evidencia o efeito causado pela estrutura da paisagem nos processos ecológicos. A estrutura vertical busca entender as interações de uma comunidade com o sistema abiótico (por exemplo clima e tipo de solo) num ambiente relativamente homogêneo, é o ponto de vista da ecologia de ecossistema (METZGER, 2001).

Os elementos naturais (recursos hídricos, fauna e flora) exercem papel de formação da identidade de uma unidade de paisagem, são considerados como patrimônio natural e paisagístico pela sua capacidade de proporcionar conforto psicológico e fisiológico as pessoas que deles usufruem, ao mesmo tempo são recursos ímpares no processo de compreensão das condições biofísicas da região (PIPPI; LIMBERGER; LAZAROTTO, 2008; VIEIRA, 2014).

A vegetação é o elemento com maior representação nas pesquisas envolvendo ecologia da paisagem, tal fato se justifica ao considerar a cobertura vegetal como um importante indicador das condições ambientais (SANTOS, 2002; MUCHAILH, 2007). Fragmento florestal pode ser definido como uma área onde a vegetação é predominante e se apresenta próximo ao seu estado natural, sendo essas interrompidas por diversas formas, tais como, estradas, povoados, culturas agrícolas, pastagens, montanhas, lagos, represas e em alguns casos as próprias formações vegetais podem ser consideradas barreiras naturais capazes de diminuir significativamente o fluxo de animais, pólen ou sementes. Em decorrência da atividade humana intensa, o processo de fragmentação da cobertura vegetal natural está cada vez mais presente, ocasionando a perda da biodiversidade local dentre outros impactos (SANTOS, 2002; DUCATTI et al., 2011).

O processo de fragmentação resulta em uma paisagem constituída por estruturas distintas formando um mosaico, onde é possível a identificação de três componentes horizontais básicas, a saber: i) matriz - é o elemento dominante na unidade tem a capacidade de controlar a dinâmica da paisagem, geralmente sendo reconhecida pela área ocupada com o menor grau de fragmentação, equivalendo a área mais extensa e mais conectada; ii) mancha - são áreas aparentemente homogêneas, que se distinguem das unidades vizinhas e apresentam extensões espaciais reduzidas e não-lineares; e, iii) corredor - são estruturas relativamente homogêneas de aparência linear, que ligam pelo menos dois fragmentos que originalmente eram conectados (METZGER, 2001; MUCHAILH, 2007). 
As Geotecnologias são consideradas as ferramentas apropriadas nos estudos da paisagem. São desenvolvidas para funcionar em ambientes computacionais, possibilitando a aquisição e o tratamento de dados espacialmente georreferenciados, bem como a integração de dados de diversas fontes, representado assim as informações da superfície da Terra mediante a uma aproximação dos meios bióticos e abióticos, capaz de modelar e analisar fenômenos presentes. Desta forma, o uso dos SIG pode facilitar e acelerar as tarefas e projetos de gestão e planejamento de paisagens (JERONYMO; SILVA, 2011).

Todo atributo da paisagem possui uma localização geográfica, nesse sentido os SIG são utilizados para a documentação e visualização desses atributos, bem como a interação entre eles para uma interpretação dos fenômenos da superfície. Informações genéricas (dados brutos) podem ser transformados em informações úteis e politicamente relevantes. Com a ajuda de um SIG, podemos explicar e visualizar relações espaciais, podemos representa-lás em forma de mapas. Podemos também desenvolver cenários espaciais e avaliar possíveis intervenções assim como os seus impactos (LANG; BLASCHKE, 2009).

Tendo como referência a literatura científica produzida nas últimas décadas, podemos afirmar que os profissionais têm dado uma atenção considerável à definição de áreas prioritárias para a conservação da biodiversidade. A partir de trabalhos desenvolvidos em ambiente de SIG tendo como base critérios como diversidade biológica, graus de ameaças e ecorregiões, e fundamentados na Análise da Paisagem regional é possível identificar as áreas prioritárias para a conservação da biodiversidade (ALMEIDA et al., 2007).

\section{GEOTECNOLOGIAS APLICADAS}

As Geotecnologias é um termo bastante empregado para definir um com conjunto de recursos tecnológicos que são utilizadas para a coleta, processamento, análise e oferta de produtos com referência geográfica, produtos esses que contém informações temáticas relacionadas a superfície terrestres. Nesse sentido, agregando os Sistemas de Informações Geográficas (SIG), o Sensoriamento Remoto, a Cartografia Digital entre outras, que através do processamento digital de imagens de satélites, elaboração de banco de dados georreferenciados, quantificação de fenômenos naturais, além de outras análises, proporcionam uma visão mais ampliada do ambiente (CÂMARA; MONTEIRO, 2001; MATIAS, 2001; ROSA, 2005; BORN, 2013).

De acordo com Fonseca (2008), o termo Geotecnologias se refere a uma temática ainda recente, portanto apresenta várias definições dentro da comunidade científica. Por conta disso, podendo até ser confundida com outros conceitos, pois segundo Rosa (2005) as Geotecnologias são conhecidas também como Geoprocessamento e que para a produção de informação espacial são 
necessárias quatro técnicas básicas: i) técnicas para coleta de informação; ii) técnicas de armazenamento da informação; iii) técnicas para tratamento e análise da informação; e iv) técnicas para o uso integrado da informação espacial.

Atualmente o conceito de Ciência da Geoinformação é bem emergente na área da Geografia, é definido como diferentes formas de representação computacional do espaço geográfico, ou seja, é utilizar-se de computadores como instrumentos de representação de dados espacialmente referenciados. E para tal feito é fundamental o entendimento dos fenômenos ambientais para que seja possível a tradução do mundo geográfico real para um ambiente computacional. (CÂMARA; MONTEIRO, 2001).

Os produtos de informação geográfica podem ser acompanhados de incoerências ou falhas relacionadas as informações de espacialização, dimensão e identificação dos alvos. Uma vez que, para se trabalhar em um ambiente informatizado, o espaço geográfico real foi transformado em um modelo de espaço geográfico digital e durante esse processo de modelagem podem ocorrer alterações matemáticas ou geométricas das feições, permitindo que suas representações sejam imprecisas no ambiente informatizado e consequentemente transferindo os erros para o produto final, esses erros também podem ser provocados por resíduos de informações gerados durante o processamento digital. Essa percepção é fundamental para a demonstrar as limitações dos produtos de geoinformação (FERREIRA, 2014).

O emprego das Geotecnologias experimenta um crescimento técnico-científico significativo, e está muito bem difundida nos estudos sobre o meio ambiente e os recursos naturais, porém são utilizadas também na gestão pública, em empresas privadas, no agronegócios e ações militares como subsídio para tomada de decisão e planejamento estratégico. Das Geotecnologias disponíveis podemos destacar os SIG e o Sensoriamento Remoto (BOLFE, 2006).

\subsection{Geoprocessamento}

O termo Geoprocessamento pode ser definido como ramo da ciência onde são utilizados aplicativos (normalmente SIG), equipamentos (computadores), dados de diversas fontes e profissionais especializados para o processamento de informações georreferenciadas (PIROLI, 2010). Geoprocessamento é uma tecnologia de caráter interdisciplinar capaz de concentrar o conhecimento de diferentes disciplinas científicas em um único ambiente para o estudo de fenômenos ambientais e urbanos (CÂMARA; MONTEIRO, 2001).

Como dito anteriormente é comum encontrar na literatura que o Geoprocessamento é sinônimo de Geotecnologias. Porém tal equívoco não deve persistir, uma vez que o geoprocessamento é definido como um conjunto técnicas operando dados georreferenciados para a 
produção de informação. Portanto não se deve confundir tecnologias de manipulação e coleta de dados espaciais com o processamento propriamente dito desses dados. Nesse contexto é sensato afirmar os dois conceitos são complementares um ao outro, uma vez que para gerar informações (processamento de dados), há necessidade de produção de dados inicias que em estado bruto não possui muita relevância, ou seja, o geoprocessamento é uma ferramenta da geotecnologia para produção de informação significativa (CÂMARA; MONTEIRO, 2001; XAVIER-DA-SILVA, 2009).

A utilização de ferramentas de Geoprocessamento é aplicável a qualquer setor que trabalhe com informações que possam ser relacionadas a pontos específicos da superfície territorial, o que justifica sua vasta difusão nos órgãos públicos, entidades privadas e não governamentais. Tal ferramenta tem se tornado indispensável em projetos e estudos relacionados ao meio ambiente. A possibilidade de processamento simultâneo de grandes quantidades de dados, favorecem para um suporte essencial na tomada de decisão em ações que envolvam planejamento e manejo dos recursos naturais (GOMES et al., 2001; FERREIRA, 2006; HAMADA; GONÇALVES, 2007).

\subsection{Sensoriamento Remoto}

Sensoriamento Remoto é a técnica que permite a aquisição de informações relativas aos recursos e fenômenos naturais da Terra pelos sensores instalados a bordo de plataformas em altitude (balões, aeronaves e satélites) que coletam e analisam a energia eletromagnética refletida, emitida ou retroespalhada pelos alvos, energia essa geralmente proveniente da luz Solar, como ilustrado na Figura 2. A coleta via sensores instalados em satélites orbitais é forma mais vantajosa de aquisição dessas informações, uma vez que possibilitam a coleta de dados de grandes áreas em pouco tempo com períodos de repetição de coleta de dados (MENESES; ALMEIDA, 2012; LORENZZETTI, 2015).

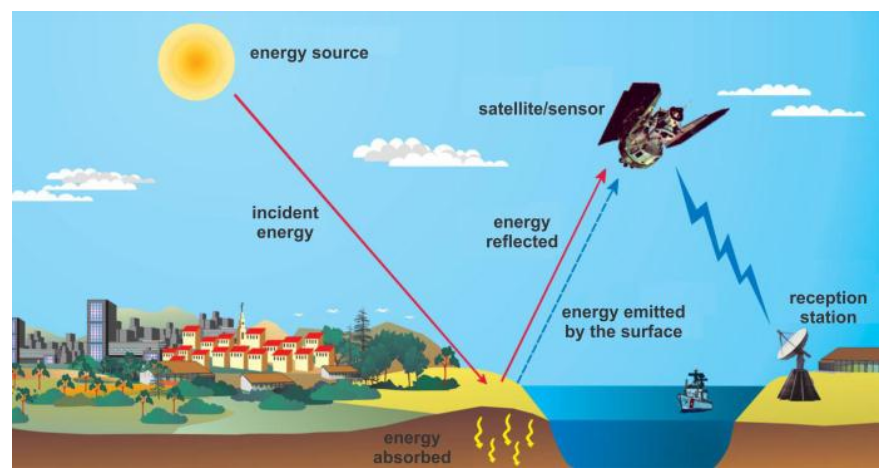

Figura 2 - Esquematização do Sensoriamento Remoto. Fonte: Florenzano (2011). 
A energia emitida pela radiação Solar possui uma grande amplitude de ondas eletromagnéticas, chamada de espectro eletromagnético. A sua interação (reflexão, absorção e transmissão) com os objetos da superfície da terra é modificada em proporção a variação ao comprimento e frequência da radiação e as características biofísica e químicas dos alvos. Nesse sentido os sensores são equipados para registrar a energia refletida em diferentes faixas do espectro eletromagnético, disponibilizando os dados em bandas espectrais distintas, para serem trabalhadas de acordo com as necessidades (BRASIL, 2000; FLORENZANO, 2011).

A análise da superfície terrestre via Sensoriamento Remoto é mais desenvolvida nos estudos envolvendo os recursos naturais como a água, os solos, as rochas e a vegetação. A exploração da interação da vegetação com a radiação eletromagnética nos permite identificar forma qualitativa a fisiologia vegetal do alvo, bem como o crescimento e produção vegetal de uma determinada cultura e também a estimativa de desflorestamento de uma região, tudo isso a partir de metodologias que estão em constante desenvolvimento (PONZONI; SHIMABUKURO; KUPLICH, 2012).

Sensoriamento Remoto é a ciência através da qual transformamos dados de radiância de uma superfície em informações sobre os objetos que a compõem, e por constar informações fora do espectro do visível (humano) as técnicas de visualização são insuficientes para analisar todos os dados contidos nas imagens. Dessa forma tendo a necessidade da utilização de técnicas computacionais de Processamento Digital de Imagem para a tradução dos dados, destacando as técnicas de Pré-Processamento, Realce e Análise Digital de imagem (NOVO, 2010).

\subsection{Sistemas de Informações Geográficas (SIG)}

É definido por Câmara e Monteiro (2001) como aplicativos de computador nos quais a sua característica principal é a capacidade de efetuar análise de informações geográficas e a sua representação espacial. Os SIG representam um dos principais componentes das geotecnologias, são neles que os dados contendo informações da superfície da terra são tratados para elaboração de mapas, gráficos, tabelas e relatórios que representam digitalmente o mundo real. A configuração dos SIG é caracterizada pela interação dos equipamentos, dados, programas computacionais, recursos humanos e métodos (TÔSTO et al., 2014; FERREIRA, 2006).

A principal diferença de um SIG para um sistema de informação convencional é sua capacidade de manipular dados de duas naturezas como: i) dados geométricos - representados por meio de entidades gráficas que representam os componentes do mundo real que se deseja analisar; e ii) dados descritivos - compostos por tabelas que contém informações numéricas, ou de texto, que descrevem características das entidades gráficas. Dessa forma os dados podem ser associados por 
um sistema interligado de representação e descrição (CASANOVA et al., 2005; DIAS; BATISTA, 2008).

A estrutura dos dados é o modo pelo qual as entidades gráficas são representadas e armazenadas em um ambiente SIG (HAMADA; GONÇALVES, 2007). E de acordo com Rosa (2013) e Tôsto et al. (2014) são descritas em dois tipos básicos:

- Vetorial ou "vector" - representado por um ou mais pares de coordenadas para definir o objeto ou limite da feição de interesse, onde o ponto simboliza o elemento fundamental, capaz de reproduzir uma linha entre um ponto inicial e um ponto final, que por sua vez pode formar polígono através de uma linha fechada com os pontos inicial e final sobrepostos; e,

- Matricial ou "raster" - modelado por uma malha quadriculada regular onde as feições são construídas célula a célula, ou seja, por uma matriz de valores, nesse caso a célula indica a unidade elementar cujo o seu tamanho é denominado de resolução espacial, sendo essa unidade relativa a área da superfície da terra.

Para a produção de informações geográficas é necessário "alimentar" os SIG com dados sobre o mundo real, sistematizado na Figura 3, com isso transformando as informações complexas constituídas de diversos elementos em um produto para representação específica. O desmembramento dos elementos em camadas permite o tratamento das informações em arquivos separados o que possibilita a representação da superfície terrestre por temas, facilitando a visualização das informações pelos consumidores (FERREIRA, 2006).

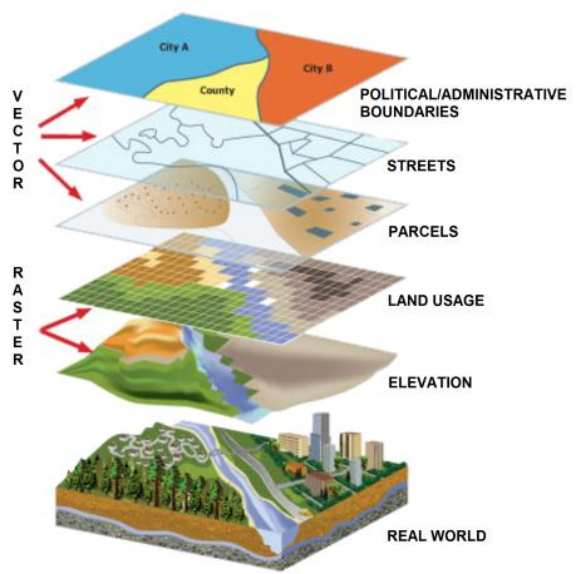

Figura 3 - Ilustração dos dados que alimentam os SIG. Fonte: adaptado de EUA (2016).

O principal alicerce dos SIG é banco de dados geográfico, onde as informações geográficas são armazenadas, gerenciadas e processadas em um único ambiente computacional. Sua estrutura permite o trabalho com dados de fontes distintas, contendo informações de geometrias e de 
descrições dos elementos que representam as características do mundo real. Destacando a capacidade de se relacionar com um grande volume de dados de forma eficiente (CASANOVA et al., 2005; PIROLI, 2010).

\section{REGIÃO HIDROGRÁFICA VIII (RH-VIII)}

O entendimento de bacia hidrográfica como unidade territorial de gestão e planejamento ambiental é bastante utilizado pelos profissionais e autores do ramo. Tal fato se justifica pela capacidade de reconhecer e estudar a integração de atributos naturais e culturais que refletem seus resultados diretamente dentro dos limites da bacia. A partir da promulgação da Lei Federal $n^{\circ}$. 9.433/97 que dispõe sobre a Política Nacional de Recursos Hídricos (PNRH), esse conceito tomou força e foi definitivamente absorvido quando o assunto é gestão dos recursos naturais (ROSS; PRETTE, 1998; SANTOS; RIZZI, 2010; ABREU et al., 2011).

A RH-VIII, conjunto de bacias hidrográficas e mananciais de água doce de alto valor ecossistêmico, está localizada na faixa costeira central-norte do Estado do Rio de Janeiro, situada entre dois polos de desenvolvimento, ao sul turístico-comercial e ao norte petrolífero-canavieiro, drenando uma área de $2.013 \mathrm{~km}^{2}$ abrangendo os municípios de Macaé, Nova Friburgo, Casimiro de Abreu, Rio das Ostras, Conceição de Macabu e Carapebus. Sendo limitada pelas bacias do Rio Macabu, do Rio São João, do Rio Macacu, do Rio Bengala e com o Oceano Atlântico. O principal curso d'água é rio Macaé onde é mensurada uma extensão total de $136 \mathrm{~km}$, suas nascentes encontram-se na Serra de Macaé de Cima, a $1.560 \mathrm{~m}$ de altitude, próximo ao pico do Tinguá no município de Nova Friburgo e desaguando no Oceano Atlântico no município de Macaé, demonstrado na Figura 4 (CBH MACAÉ/OSTRAS, 2012a).

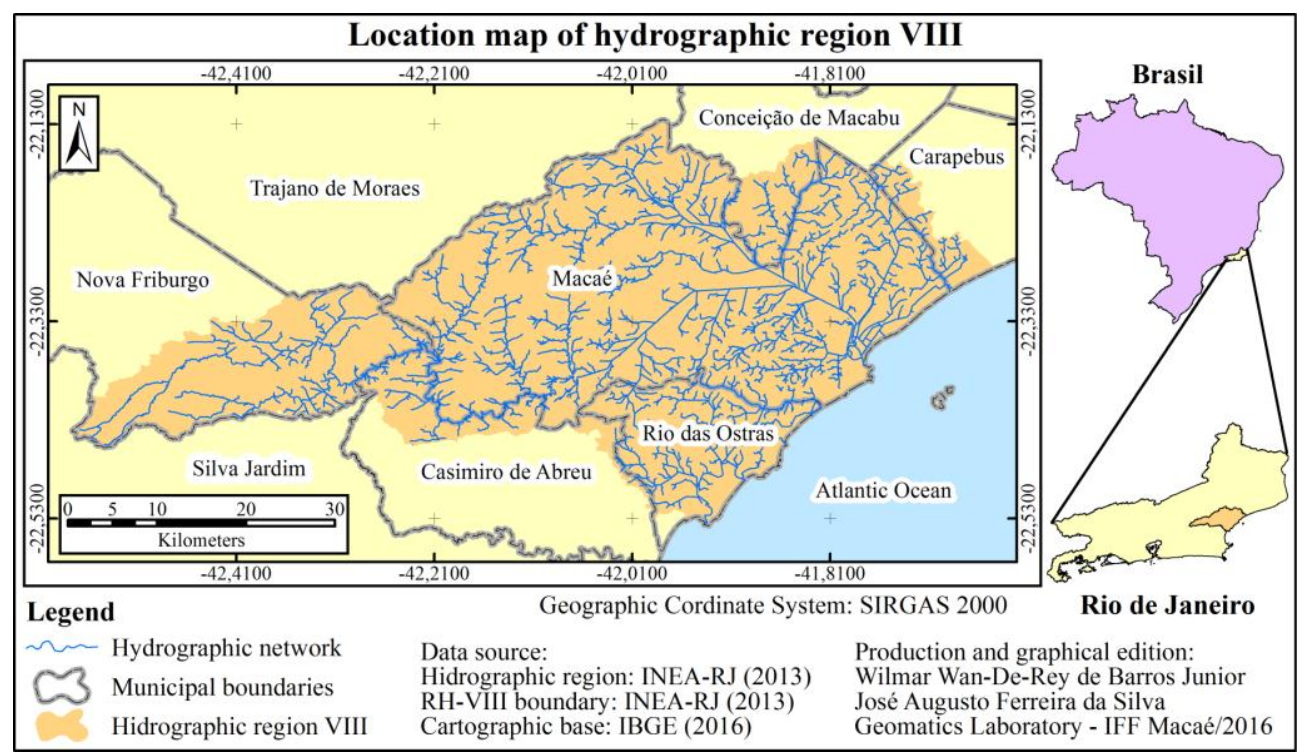

Figura 4 - Mapa de localização da região hidrográfica VIII. Fonte: Autores, 2016. 
A RH VIII tem uma grande relevância para a região devido aos usos de seus recursos em diversas atividades, dentre elas: abastecimento público, agricultura e geração de energia. Porém podemos destacar a sua importância a nível nacional, pois a bacia também abastece as indústrias de petróleo instaladas na região (BENASSULY, 2009). Na região serrana da bacia o destaque é para exploração turística que vem crescendo a cada ano, particularmente nos distritos de Lumiar e São Pedro da Serra, em Nova Friburgo, e do Sana, em Macaé (PINHEIRO, 2008).

No panorama ambiental a RH-VIII apresenta impactos negativos bastantes significativos e as feições atuais dos ecossistemas são reflexos da evolução histórica dos diferentes tipos de ocupação e exploração da região, desde o desenvolvimento agrícola no período colonial e recentemente com a expansão das áreas urbanas em consequência da indústria do petróleo e desenvolvimento turístico da região. Dentre os impactos resultantes pela ação antrópica, podemos destacar o represamento e retilinização do curso d'água, uso e ocupação de áreas restritas e a retirada da cobertura vegetal para atividade agrícola, apesar disso na bacia, há significativos remanescentes de Mata Atlântica em seu interior, que requerem de uma atenção voltada para a sua conservação. A porção do alto curso do rio Macaé é a que se encontra em melhor estado de conservação ambiental, tal feito tem relação direta com a presença de Unidades de Conservação da Natureza no local (CBH MACAÉ/OSTRAS, 2012a).

O processo de ocupação local é evidenciado desde a época do Brasil Colônia e desde então o homem vem contribuindo para transformação da paisagem na região. A degradação ambiental teve início com o desmatamento terras para exploração do café e cana-de-açúcar, e posteriormente o declínio econômico dessas atividades na década de 1940 levaram a substituição nessas terras pela atividade agropecuária. Apesar disso ocorreu um aumento considerável da ocupação humana na região a partir da década de 1970 com a descoberta do petróleo da Bacia de Campos e a instalação da Petrobras na cidade de Macaé (MARÇAL; LUZ, 2003; MOTÉ; MARÇAL; BONATTO, 2006; SILVA; BEZERRA; GUERRA, 2012).

De acordo com Moté, Marçal e Bonatto (2006) pode ser feito uma associação dos tipos de uso e cobertura da terra com cada compartimento da bacia do Rio Macaé (alto, médio e baixo curso), apresentados da seguinte forma: i) alto curso - representa a porção mais preservada da bacia, porém a especulação imobiliária e o turismo contribuem consideravelmente para degradação ambiental, além de outras atividades em menor proporção como a agropecuária; ii) médio curso - o uso é predominante agropecuário apresentando pequenos fragmentos de mata; e iii) baixo curso - o desenvolvimento da urbanização foi a atividade que transformou boa parte desse compartimento, descaracterizando áreas de mangue e restinga. 
Entre as décadas de 1940 e 1980 o governo federal através do antigo Departamento Nacional de Obras e Saneamento (DNOS), iniciou uma série de intervenções sobre os canais fluviais em diversas planícies de inundação no Estado do Rio de Janeiro, com o objetivo de minimizar os problemas relacionados as enchentes, evitar a proliferação da malária e aumentar as terras secas favorecendo a atividade agropecuária. Por consequência cerca de $60 \mathrm{~km}$ do rio Macaé foram retilinizados, além de trechos dos seus afluentes como os rios São Pedro, D’Antas e o canal Jurumirim. A retilinização desses canais minimizou os problemas relacionados a saneamento e contribuiu para atividade agropecuária nas terras antes alagadiças, porém não resolveu o problema com enchentes e além disso causou alguns impactos ambientais como assoreamento dos rios, alteração da hidrodinâmica na zona estuarina, diminuição do pescado e outros (REGO, 2010; ASSUMPÇÃO; MARÇAL, 2012).

Cabe destacar que na bacia do rio Macaé, mais precisamente na sub-bacia do rio São Pedro foram implantados dois aproveitamentos hidroelétricos: i) a Usina Hidroelétrica (UHE) Glicério que encontra-se desativada; ii) e a UHE Macabu, que recebe águas da bacia hidrográfica da Lagoa Feia, sendo essa transposição viabilizada por um represamento do rio Macabu na localidade de Tapera no município de Trajano de Moraes, causando uma série de conflitos, entre eles a diminuição da disponibilidade hídrica a jusante da represa (PINHEIRO, 2008; WERNECK, 2010; FREITAS et al., 2014).

No âmbito da gestão dos recursos hídricos a RH-VIII compreende as bacias hidrográficas dos rios Macaé e das Ostras e da Lagoa de Imboassica, juntamente com pequenos córregos e lagoas litorâneas (CERHI-RJ, 2013). Dessa forma tendo como órgão consultivo, deliberativo e normativo o CBH Macaé/Ostras - Comitê de Bacia Hidrográfica dos Rios Macaé e das Ostras. Que se caracteriza por um conjunto de entidades representantes do Poder Público, da sociedade civil organizada e dos usuários, aderindo os princípios da gestão integrada, descentralizada e participativa. Tal modelo de gestão dos recursos hídricos foi instituído tendo como referência a experiência da França e legalmente instituído pela Lei Federal n 9.394/97 - PNRH, e Lei Estadual n 3.599/99 - Política Estadual dos Recursos Hídricos (PNERH) (REGO, 2010; SILVA, 2015).

É relevante informar que a RH-VIII foi uma das primeiras do estado do Rio de Janeiro a implementar o referido sistema de gestão, tal fato foi motivado pela necessidade de garantir água de qualidade aos usuários e a pressão de instituições ambientalistas preocupadas com alto dinamismo urbano na região e sua capacidade de degradação dos recursos naturais (PORTELA; BRAGA, 2006). A respeito das ações do CBH Macaé/Ostras podemos destacar a dedicação para elaboração do seu Plano de Recursos Hídricos, que segundo ANA (2016) é um instrumento da PNRH onde é estabelecido ações estratégicas voltadas a gestão dos recursos hídricos de uma determinada bacia. 
Durante a elaboração do Plano de Recursos Hídricos da Região Hidrográfica VIII foi identificado a necessidade de formulação de subsídios para programas de conservação e recomposição da biodiversidade que é especificado como a identificação de zonas compatíveis com as seguintes categorias de manejo: i) áreas de preservação; ii) áreas para conservação; e iii) áreas de desenvolvimento (ordenamento territorial) (CBH MACAÉ/OSTRAS, 2012b).

\section{GEOPROCESSAMENTO COMO FERRAMENTA DE APOIO A GESTÃO E PLANEJAMENTO TERRITORIAL}

A sociedade contemporânea apresenta padrões insustentáveis de produção e consumo, pois acredita que o crescimento econômico é melhor caminho para obtenção de melhores condições de vida, gerando danos sociais e ambientais que ironicamente prejudicam o bem-estar e qualidade de vida. Especialistas afirma que desde a década de 80 a biosfera não suporta a demanda humana no que diz respeito a produção de recursos consumidos e assimilação de resíduos gerados (COSTA et al., 2004; SOUSA; TAVARES, 2013; DANTAS et al., 2014).

O desenvolvimento da sociedade ocorreu de forma desordenada em relação a ocupação das terras, e foi sucedida em áreas mais acessíveis sem a devida preocupação quanto as condições do ambiente, seja pela falta de conhecimento ou pela necessidade, promovendo diversos impactos negativos que resultaram na redução da qualidade de vida. Nesse sentido, ao analisar as características do espaço físico é possível identificar um uso apropriado para o mesmo, configurando um planejamento para uso das terras. Tal processo se torna fundamental para mitigar os problemas decorrentes do mau uso dos recursos naturais, procurando a sua conservação (PEDRON et al., 2006; CORSEUIL; CAMPOS, 2007).

As questões ambientais passam a ter notoriedade na década de 60, onde a busca pelo lucro a qualquer custo gerou uma queda na qualidade ambiental, que por sua vez estimulou a realização de movimentos de proteção à natureza. Nos anos 90 o assunto atinge o ápice com o desenvolvimento da gestão ambiental, que pode ser entendida como o conjunto de procedimentos que visam à conciliação entre desenvolvimento e qualidade ambiental (KRAETZIG 2008; MEDEIROS; GIORDANO; REIS, 2012). Segundo Floriano (2007) a gestão de um ambiente tem como finalidade a manutenção das estruturas e funções ecológicas do meio, logo seu objetivo é a conservação desse ambiente.

A conservação ambiental é um conceito amplamente utilizado para retratar as ações de manejo adequado dos recursos de um ambiente, é o uso racional dos recursos naturais e espécies vivas, favorecendo o equilíbrio do meio ambiente e garantindo a variedade e consumo dos serviços ambientais. Esse conceito está associado à sobrevivência de todas as espécies, inclusive da espécie 
humana que é a maior consumidora dos recursos naturais e que menos contribui para a sustentação dos mesmos (PINHEIRO; KURY, 2008).

A restrição ao uso de uma área não tem função apenas de preservar a vegetação ou a biodiversidade, mas sim uma função socioambiental bem mais abrangente de garantir os serviços ambientais com qualidade, assegurar o bem-estar das populações humanas e impedir a ocupação de áreas de risco como no caso das Áreas de Preservação Permanente (APP) previstas na Lei Federal 12.651/2012 (Código Florestal Brasileiro) (SCHÄFFER et al., 2011).

A gestão ambiental evoluiu na área de conhecimento sobre o meio ambiente, agregando os conhecimentos das áreas de ciências biológicas, geografia, geologia e das áreas de ciências exatas, permitindo uma condução para o uso racional dos recursos naturais. Dentro desse conceito evolucionário de administração do meio ambiente, a área de conhecimento denominada de geoprocessamento se configura como um instrumento de grande relevância para a gestão dos recursos naturais, criando novas possibilidade de análise ambiental, antes totalmente impensáveis. A área apresenta-se como uma possibilidade de exploração e estabelecimento de novos conhecimentos científicos na área ambiental (SILVEIRA, 2004).

Um dos motivos principais para o desenvolvimento dos primeiros SIG foi o meio ambiente, devido à sua grande quantidade de ferramentas aplicadas a questões ambientais, faz da causa, tema predominante nos estudos desenvolvidos nos sistemas. Possuindo aplicações em: na expansão urbana descontrolada, no desmatamento, na diminuição dos impactos ambientais pelo planejamento espacial, no uso e ocupação da terra (LONGLEY et al., 2013).

Segundo Silveira (2004), a gestão ambiental pode ser entendida como um processo de tomada de decisões onde as questões ambientais são as prioridades de um sistema. Nesse caso, a tomada de decisão consiste na busca da alternativa que apresente o melhor desempenho, a melhor avaliação, ou ainda a melhor aliança entre as expectativas daquele que tem o poder de decidir e suas disponibilidades em adotá-la.

A tomada de decisão pode ser apoiada por diversas metodologias, dentre elas, os métodos baseados em AMC se destacam e são bastantes utilizados para aplicação em planejamento ambiental. Eles destinam-se a investigar um número de possibilidades frente a múltiplos critérios e prioridades conflitantes, auxiliando na modelação e a agregação das preferências dos atores. É um instrumento que permite apoiar o grupo decisor a reavaliar seus pontos de vista mediante a uma técnica consagrada. Permite incorporar, sistematicamente, aspectos sociais, econômicos, técnicos e ambientais. Esses métodos buscam otimizar a decisão por meio da maximização dos objetivos. A solução ótima é aquela que maximiza o valor das alternativas ou pontos de vista considerados (SANTOS, 2004). 
5.1 Utilizando o SIG como apoio à tomada de decisão

Alguns SIG adquiriram uma combinação bem-sucedida com as técnicas de suporte na tomada de decisão, ambas ferramentas se completam perfeitamente. O SIG permite a integração com outras tecnologias como o sensoriamento remoto, GPS, Computer Aided Design (CAD), dentre outras, e a sua habilidade de efetuar diversas tarefas utilizando tanto os dados espaciais quanto os atributos armazenados nos dados, propicia para uma melhor compreensão do processo de tomada de decisão (BIJU, 2015).

Uma tomada de decisão implica em assumir riscos exigindo bons processos para alcançar os melhores resultados. Nessa linha de raciocínio, as decisões relacionadas às questões ambientais demanda coerência e comprometimento, pois a temática está frequentemente associada a uma incerteza considerável e o seu tratamento ultrapassam os objetivos propostos inicialmente, podendo comprometer outros usuários (BORN, 2013).

Os SIG são complementares na tomada de decisão e em alguns casos apresentam inclusive módulos de análise geográfica participativa, sendo empregado em diversas áreas, principalmente nas questões ambientais, planejamento urbano, como também na indicação de áreas suscetíveis a implantação de diferentes empreendimentos (HASENACK, 1995; DONEVSKA et al., 2011).

De acordo com Westmacott (2001) e Davis e McDonald (1993) apud Born (2003), existe uma variedade significativa de sistemas de apoio à decisão, porém a estrutura tradicional é constituída por três componentes básicos:

- Interface com usuário: diz respeito à única parte do sistema de apoio à decisão com a qual o usuário terá contato, exercendo uma importante função na utilização do sistema. Além de interpretar uma grande variedade de solicitações do tomador de decisões, a interface é capaz também de justificar resultados da base de dados e modelos.

- Base de dados: nela estão contidas as informações de natureza distintas, que serão utilizadas para alimentar os modelos temáticos.

- Base de modelos: são as soluções possíveis para um problema. Dependendo da necessidade do usuário pode ser diversificado por modelos estruturais, matriciais, numéricos, espaciais, dentre outros.

\subsection{Análise por Múltiplos Critérios (AMC)}

Para a tomada de decisão, é necessário levar em consideração diversos critérios para avaliar um conjunto de alternativas que foram designadas para a resolução de um dado problema, pode-se então afirmar que ele se encontra num processo de decisão por multicritério (LEONETI, 2012). 
A AMC, é uma metodologia que tem sido amplamente utilizada em decisões relacionadas a problemas que possuem diferentes alternativas e critérios, facilitando a tomada de decisão das partes interessadas. As alternativas costumam ser avaliadas através de uma atribuição de valores de acordo com as características que o alvo apresenta. Estes alvos são caracterizados pelas suas preferências ao que diz respeito aos critérios e das alternativas que são avaliadas. Portanto, muitos problemas envolvendo as análises espaciais, acabam por dar origem à tomada de decisão por análise de multicritério em conjunto com o SIG (BOROUSHAKI; MALCZEWSKI, 2010).

O apoio a tomada de decisão via AMC possui diferentes técnicas de aplicação, dentre elas destaca-se a Analytic Hierarchy Process (AHP), em português Processo Analítico Hierárquico (PAH), que pode ser executada a partir da lógica booleana e a combinação linear ponderada. Esses métodos são facilmente aplicados a problemas pertinentes à análise de informações geográficas (BIJU, 2015).

A técnica de PAH surgiu no final da década de 60 e foi desenvolvido pelo matemático Thomas L. Saaty. É baseado em princípios qualitativos e quantitativos, onde os critérios são organizados de maneira hierárquica, atribuindo a cada critério um peso numérico ou prioridade para uma análise sistemática par a par, gerando uma matriz de comparação que ao ser derivada em relação a cada alternativa, permite que seja utilizada no apoio a tomada decisão (SAATY, 1987; BRIOZO; MUSETTI, 2015).

A atribuição dos valores aos critérios é realizada a partir da: i) lógica booleana - os critérios são analisados por uma condição binária (falso ou verdadeiro), pode se dizer que é uma definição mais simples; ii) Combinação Linear Ponderada (CLP) - consiste em dar pesos aos critérios de acordo com sua importância e são combinados por uma média ponderada, é uma metodologia de padronização dos fatores para uma escala numérica comum (EASTMAN, 1998; JERONYMO, 2012).

Os critérios da AMC podem ser de dois tipos: restrições e fatores. Os fatores são características que indicam algum grau de aptidão ou uma limitação relativa para os objetivos propostos inicialmente, compreendendo todas as regiões geográficas (método da CLP). As restrições são as feições que limitam totalmente espaços específicos, determinando em aptos ou não aptos (lógica booleana) (BORN, 2003; JERONYMO, 2012).

\section{CONCLUSÕES}

A Ciência da Geoinformação é um termo emergente onde utilizamos computadores para gerar e representar os elementos contidos no espaço geográfico, esses elementos podem ser identificados e avaliados separadamente, produzindo informações relevantes que podem ser 
armazenadas em ambientes de SIG e posteriormente processadas nos módulos de AMC, onde é permitido a atuação dos elementos como critérios.

Para criar um procedimento de AMC visando o ordenamento territorial, deve-se avaliar a aptidão dos critérios (elementos) em relação ao uso indicado, a exemplo das APP que possui restrição ao uso para a atividade humana enquanto as estradas indicam uma tendência ao desenvolvimento. Portanto pode-se utilizar o método de PAH, onde os critérios são avaliados de acordo com as suas prioridades.

A aplicação do princípio de Análise da Paisagem é de extrema relevância para avaliação dos critérios, uma vez que é conceituada na compreensão do dinamismo entre os elementos da natureza, sendo possível reconhecer as fragilidades e os potenciais das unidades com isso gerando indicadores relacionados aos elementos.

Em síntese os métodos aqui apresentados são satisfatórios para serem aplicados ao planejamento territorial de uso das terras, dessa forma se apresentado como uma solução as demandas criadas de ordenamento territorial, não somente para a RH-VIII, como também para outras regiões.

\section{REFERÊNCIAS}

ABREU BS, NETO SF, MELO AA, MELO GKRMM, LIMA PCS, MORAIS PSA, et al. Diagnóstico socioeconômico da microbacia hidrográfica Riacho da Igreja, Cabaceiras/PB. Educação Agrícola Superior. 2011; v.26, n.1, p.25-29.

ALMEIDA D, SCHU P, BALEIXO RR, ROCHA CH. Avaliação da eficácia de modelo para definição de áreas prioritárias para a conservação da natureza. In: Anais do $8^{\circ}$ Congresso de Ecologia do Brasil; 2007; Caxambu.

ANA - AGÊNCIA NACIONAL DE ÁGUAS (Brasil). Planejamento de Recursos Hídricos [Internet]. 2016. [acessado em: 10 jul. 2016]. Disponível em: http://www2.ana.gov.br/Paginas/institucional/SobreaAna/planejamentoRH.aspx

ASSUMPÇÃO AP, MARÇAL MS. Retificação dos canais fluviais e mudanças geomorfológicas na planície do Rio Macaé (RJ). Revista de Geografia. 2012; v.29, n.3, p.19-36.

BENASSULY CCL. Avaliação de redes de monitoramento de recursos hídricos: estudo aplicado às águas superficiais na bacia do Rio Macaé [dissertação]. Campos dos Goytacazes: Curso de Engenharia Ambiental/IFF. 2009. 100p.

BERTRAND G. Paisagem e geografia física global: esboço metodológico. Ra'e Ga. 2004, n.8, p.141-152. 
BIJU BP. Utilização do sistema de informação geográfica (SIG) na indicação de possíveis áreas aptas à disposição de resíduos de construção civil [dissertação]. Curitiba: Curso de Engenharia Civil/UTFPR. 2015. 113p.

BOLFE EL. Geotecnologias aplicadas à gestão de recursos naturais. In: Anais do $3^{\circ}$ Simpósio Regional de Geoprocessamento e Sensoriamento Remoto; 2006; Aracaju.

BORN V. Avaliação da aptidão de áreas para a instalação de aterro sanitário com o uso de ferramentas de apoio à decisão por múltiplos critérios [TCC]. Lajeado: Curso de Engenharia Ambiental/Univates. 2013. 103p.

BOROUSHAKI S, MALCZEWSKI J. Measuring consensus for collaborative decision-making: A GIS-based approach. Computers, Environment And Urban Systems. 2010; n.34, p.322-332.

BRASIL. IBGE - Instituto Brasileiro de Geografia e Estatística. Ministério do Planejamento. Introdução ao Processamento Digital de Imagens. Rio de Janeiro: IBGE; 2000. 92p.

BRIOZO RA, MUSETTI MA. Método multicritério de tomada de decisão: aplicação ao caso da localização espacial de uma Unidade de Pronto Atendimento - UPA 24 h. Gest. Prod. 2015; v.22, n.4, p.805-819.

CÂMARA G, MONTEIRO AMV. Conceitos básicos em ciência da geoinformação. In: CÂMARA G, DAVIS JUNIOR CA, MONTEIRO AMV. Introdução à ciência da geoinformação. São José dos Campos: INPE; 2001. p.7-41.

CARVALHO DF, SILVA LDB. Hidrologia: Capítulo 3. Bacia Hidrográfica [Internet]. 2006. [acessado em 30 de nov. 2015]. Disponível em: http://www.ufrrj.br/institutos/it/deng/leonardo/downloads/APOSTILA/HIDRO-Cap3-BH.pdf

CASANOVA MA, CÂMARA G, DAVIS JUNIOR CA, VINHAS L, QUEIROZ GR. (Ed.). Bancos de Dados Geográficos. Curitiba: MundoGEO;2005. 504p.

CAZULA LP, MIRANDOLA PH. Bacia hidrográfica - conceitos e importância como unidade de planejamento: um exemplo aplicado na bacia hidrográfica do Ribeirão Lajeado/SP - Brasil. Associação dos Geógrafos Brasileiros. 2010; v.7, n.12, p.101-124.

CBH MACAÉ/OSTRAS - Comitê de Bacia Hidrográfica dos Rios Macaé e das Ostras (Rio de Janeiro). Secretaria Estadual do Ambiente. Elaboração do plano de recursos hídricos da região hidrográfica Macaé e das Ostras: Relatório de caracterização da região hidrográfica Macaé e das Ostras. 2012a. 91 p.

CBH MACAÉ/OSTRAS - Comitê de Bacia Hidrográfica dos Rios Macaé e das Ostras (Rio de Janeiro). Secretaria Estadual do Ambiente. Elaboração do plano de recursos hídricos da região hidrográfica Macaé e das Ostras: Plano de trabalho consolidado. 2012b. 149p. 
CERHI-RJ - CONSELHO ESTADUAL DE RECURSOS HÍDRICOS (Rio de Janeiro). Secretaria Estadual do Ambiente. Aprova nova definição das regiões hidrográficas do Estado do Rio de Janeiro e revoga a resolução CERHI n ${ }^{\circ} 18$ de 08 de novembro de 2006 [Internet]. 2013. [acessado em: 10 jul. 2016]. Disponível em: http://www.inea.rj.gov.br/cs/groups/public/documents/document/zwew/mdq4/ edisp/inea0048930. pdf

CORSEUIL CW, CAMPOS S. Análise de adequação do uso das terras por meio de técnicas de geoprocessamento e de análise de multicritérios. In: Anais do $13^{\circ}$ Simpósio Brasileiro de Sensoriamento Remoto; 2007; Florianópolis.

COSTA AFM, STUTZ BL, MOREIRA GO, GAMA MM. Sociedade atual, comportamento humano e sustentabilidade. Caminhos de Geografia. 2004; v.5, n.13, p.209-220.

DANTAS ME, ARMESTO RCG, SILVA CR, SHINZATO E. Geodiversidade e análise da paisagem: uma abordagem teórico-metodológica. Terræ Didatica. 2015; v.11, n.1, p.4-13.

DANTAS MK, PACHECO LM, LIBONI LB, CALDANA ACF. Análise dos gastos públicos com gestão ambiental no Brasil. Revista de Gestão Social e Ambiental. 2014; v.8, n.3, p.52-68.

DIAS NW, BATISTA GT. Geoprocessamento: uma ferramenta para o desenvolvimento regional sustentável [Internet]. 2008. [acessado em: 20 jul. 2016]. Disponível em: https://www.researchgate.net/publication/27458511_Geoprocessamento_uma_ferramenta_para_o_d desenvolviment_regional_sustentavel

DONEVSKA KR, GORSEVSKI PV, JOVANOVSKI M, PESEVSKI I. Regional non-hazardous landfill site selection by integrating fuzzy logic, AHP and geographic information systems. Environ Earth Sci. 2011; v.67, n.1, p.121-131.

DUCATTI A, PÉRICO E, AREND U, CEMIN G, HAETINGER C, REMPEL C. Análise da paisagem por Sistemas de Informação Geográfica (SIGs) e métricas de paisagem como subsídio para tomada de decisões em nível ambiental. Espacios. 2011; v.32, n.1, p.35-36.

EASTMAN JR. IDRISI for Windows: Introdução e exercícios tutoriais. Hasenack H, Weber E, tradutores. Porto Alegre: UFRGS, 1998. 240p.

ESTÊVEZ LF, CUNICO C, MEZZOMO MM, BIESEK AS, MAGANHOTTO R. Análise da paisagem da bacia hidrográfica do Rio Marumbi, Morretes-PR: unidades de paisagem, fragilidade potencial e hemerobia. Ra'e Ga. 2011; n.23, p.428-447.

EUA. SAN BERNARDINO COUNTY. Geographic Information System: Geoprocessing Services [Internet]. 2016. [acessado em: 12 jul. 2016]. Disponível em: http://www.sbcounty.gov/isd/main/services/gis.aspx 
FERREIRA MC. Paradigmas e modelos para a informatização geográfica em SIG. In: FERREIRA MC. Iniciação à análise geoespacial. São Paulo: UNESP; 2014. p.50-52.

FERREIRA NC. Apostila de sistema de informações geográficas [Internet]. 2006. [acessado em: 20 jul. 2016]. Disponível em: http://www.faed.udesc.br/arquivos/id_submenu/1414/apostila_sig.pdf LORENZANO TG. Iniciação em Sensoriamento Remoto. $3^{\mathrm{a}}$ ed. São Paulo: Oficina de Textos; 2011. 128p.

FLORIANO EP. Políticas de gestão ambiental. $3^{\text {a }}$ ed. Santa Maria: UFSM; 2007. 111p.

FONSECA MF. Geotecnologias aplicadas ao diagnóstico do uso da terra no entorno do Reservatório de Salto Grande, município de Americana (SP), como subsídio ao planejamento territorial [dissertação]. Campinas: Curso de Geografia/UEC. 2008. 82p.

FREITAS LN, FERREIRA MIP, PINHEIROS K, MELLO DS, OLIVEIRA VPS. Barragem e transposição do Rio Macabu: conflitos gerados pelo uso da água e a integração de bacias hidrográficas no gerenciamento de recursos hídricos. Boletim do Observatório Ambiental Alberto Ribeiro Lamego. 2014; v.8, n.2, p.57-75.

GOMES LP, COELHO OW, ERBA DA, VERONEZ M. Critérios de seleção de áreas para disposição final de resíduos sólidos. In: ANDREOLI CV, organizadores. Resíduos sólidos do saneamento: processamento, reciclagem e disposição final. Rio de Janeiro: Rima, ABES; 2001. p.145-163.

HAMADA E, GONÇALVES RRV. Introdução ao geoprocessamento: princípios básicos e aplicação. Jaguariúna: Embrapa; 2007. 52p.

HASENACK H. O geoprocessamento no processo de tomada de decisão. Boletim Gaúcho de Geografia. 1995; n.20, p.185-188.

JERONYMO CAL. Identificação de Áreas Prioritárias, com uso de Geoprocessamento, para Conservação e Recuperação Florestal da Área de Preservação Ambiental do Sana, Macaé-RJ [dissertação]. Macaé: Curso de Engenharia Ambiental/IFF. 2012. 70p.

JERONYMO CAL, SILVA JAF. Proposta de manejo de paisagem na APA do Sana (Macaé-RJ). Boletim do Observatório Ambiental Alberto Ribeiro Lamego. 2011; v.5, n.2, p.173-201.

KRAETZIG JM. Educação ambiental e inclusão de alunos com necessidades educacionais especiais: uma prática possível [monografia]. Santa Maria: Curso de Educação Ambiental/UFSM. 2008. 61p.

LANG S, BLASCHKE T. Análise da paisagem com SIG. São Paulo: Oficina de Textos; 2009. 424 p. 
LEONETI AB. Teoria dos jogos e sustentabilidade da tomada de decisão: aplicação a sistemas de tratamento de esgoto [tese]. São Carlos: Curso de Engenharia Hidráulica e Saneamento/USP. 2012. $167 \mathrm{p}$.

LONGLEY PA, GOODCHILD MF, MAGUIRE DJ, RHIND DW. Sistemas e ciência da informação geográfica. 3. ed. Porto Alegre: Bookman; 2013. 560 p.

LORENZZETTI JA. Princípios físicos de Sensoriamento Remoto. São Paulo: Blucher; 2015. 294p. MARÇAL MS, LUZ LM. Geomorfologia aplicada a classificação de unidade de paisagem na bacia do Rio Macaé - Litoral Norte Fluminense. In: Anais do $10^{\circ}$ Simpósio Brasileiro de Geografia Física Aplicada; 2003; Rio de Janeiro.

MATIAS LF. Sistema de Informações Geográficas (SIG): teoria e método para representação do espaço geográfico [tese]. São Paulo: Curso de Geografia Humana/USP. 2001. 325p.

MEDEIROS GA, GIORDANO LC, REIS FAGV. Gestão ambiental. In: ROSA AH, FRACETO LF, MOSCHINI-CARLOS V. Meio ambiente e sustentabilidade. Porto Alegre: Bookman; 2012. p.375-406.

MENESES PR, ALMEIDA $\mathrm{T}$, organizadores. Introdução ao processamento de imagens de sensoriamento remoto. Brasília: UNB; 2012. 276p.

METZGER JP. O que é ecologia de paisagens? Biota Neotropica. 2001; v.1, n.1, p.61-69.

METZGER JP, FONSECA MA, OLIVEIRA FILHO FJB, MARTENSEN AC. O uso de modelos em ecologia de paisagens. Megadiversidades. 2007; v.3, n.1, p.64-73.

MOTÉ FO, MARÇAL MS, BONATTO G. Uso e Cobertura da Terra Associado as Unidades de Relevo e Problemas Ambientais na Bacia do Rio Macaé (RJ). In: Anais do $6^{\circ}$ Simpósio Nacional de Geomorfologia; 2006; Goiânia.

MUCHAILH MC. Análise da paisagem visando à formação de corredores de biodiversidade: Estudo de caso da porção superior da bacia do rio São Francisco Falso, Paraná [dissertação]. Curitiba: Curso de Engenharia Florestal/UFPR; 2007.142p.

NOVO ELM. Sensoriamento Remoto: princípios e aplicações. 4 ${ }^{\mathrm{a}}$ ed. São Paulo: Blucher; 2010. $388 \mathrm{p}$.

PARREIRAS RO. Algoritmos evolucionários e técnicas de tomada de decisão em análise multicritério [tese]. Belo Horizonte; Curso de Engenharia Elétrica/UFMG; 2006. 166p. 
PEDRON FA, POELKING EL, DALMOLIN RSD, AZEVEDO AC, KLANT E. A aptidão de uso da terra como base para o planejamento da utilização dos recursos naturais no município de São João do Polêsine - RS. Ciência Rural. 2006; n.1,p.105-112.

PHILIPPI JUNIOR A, SILVEIRA FV. Saneamento ambiental e ecologia aplicada. In: PHILIPPI JUNIOR A, ROMÉRO MA, BRUNA GC, editores. Curso de gestão ambiental. Barueri: Manole; 2004. p.19-52.

PINHEIRO MRC. Avaliação de usos preponderantes e qualidade da água como subsídios para os instrumentos de gestão dos recursos hídricos aplicada à bacia hidrográfica do Rio Macaé [dissertação]. Campos dos Goytacazes: Curso de Engenharia Ambiental/CEFET-Campos; 2008. $151 \mathrm{p}$.

PINHEIRO MRC, KURY KA. Conservação ambiental e conceitos básicos de ecologia. Boletim do Observatório Ambiental Alberto Ribeiro Lamego. 2008; v.02, n.02, p.15-28.

PINTO NGM, CORONEL DA, LOPES MM, SILVA RA. A degradação ambiental no Brasil: uma análise das evidências empíricas. In: Anais do $1^{\circ}$ Seminário de Jovens Pesquisadores em Economia e Desenvolvimento; 2013; Santa Maria.

PIPPI LGA, LIMBERGER LRL, LAZAROTTO G. Recursos para representação e análise da paisagem. Paisagem e Ambiente: ensaios. 2008; n.25, p.105-126.

PIROLI EL. Introdução ao geoprocessamento. Ourinhos: UNESP; 2010. 46p.

PONZONI FJ, SHIMABUKURO YE, KUPLICH TM. Sensoriamento remoto da vegetação. $2^{\mathrm{a}}$ ed. São Paulo: Oficina de Textos; 2012. 176p.

PORTELA NF, BRAGA TM. Conflitos federativos em gestão de recursos hídricos no Brasil: reflexões a partir do caso da bacia do rio Macaé (RJ). Geografias. 2006; v.2, n.2, p74-85.

REGO VVBS. Cidadania e participação no Comitê de Bacia Hidrográfica dos Rios Macaé e das Ostras. Boletim do Observatório Ambiental Alberto Ribeiro Lamego. 2010; v.4, n.2, p.117-138.

ROSA R. Geotecnologias na geografia aplicada. Revista do Departamento de Geografia. 2005; n.16, p.81-90.

ROSA R. Introdução ao geoprocessamento. Uberlândia: Universidade Federal de Uberlândia; 2013. $142 p$.

ROSS JLS, PRETTE ME. Recursos hídricos e as bacias hidrográficas: âncoras do planejamento e gestão ambiental. Revista do Departamento de Geografia. 1998; n.12, p.89-121. 
SAATY TL. Risk-Its Priority and Probability: The Analytic Hierarchy Process. Risk Analysis. 1987; v.7, n.2, p.159-172.

SANTOS JSM. Análise da paisagem de um corredor ecológico na Serra da Mantiqueira [dissertação]. São José dos Campos: Curso de Sensoriamento Remoto/INPE; 2002. 176p.

SANTOS JS, RIZZI NE. Dinâmica de uso do solo da bacia hidrográfica do Rio Luís Alves, subbacia do Rio Itajaí, Santa Catarina, Brasil. Floresta. 2010; v.40, n.2, p.335-344.

SANTOS RF. Planejamento ambiental: teoria e prática. São Paulo: Oficina de Textos; 2004.

SCHÄFFER WB, ROSA MR, AQUINO LCS, MEDEIROS JD. Áreas de Preservação Permanente e Unidades de Conservação X Áreas de Risco: O que uma coisa tem a ver com a outra? Relatório de Inspeção da área atingida pela tragédia das chuvas na Região Serrana do Rio de Janeiro. Brasília: MMA; 2011. 96p.

SILVA GP. Comitês de bacias hidrográficas e vocalizações sociais por recursos hídricos no Município de Macaé - Rio de Janeiro. In: Anais do $7^{\circ}$ Seminário Internacional sobre Desenvolvimento Regional; 2015; Santa Cruz do Sul.

SILVA LFTC, BEZERRA JFR, GUERRA AJT. Implicações da mudança na cobertura vegetal em relação à erosão na sub-bacia hidrográfica do rio São Pedro - RJ. Geonorte. 2012; v.1, n.6, p.1-16.

SILVEIRA FV. Geoprocessamento como Instrumento de Gestão Ambiental. In: PHILIPPI JUNIOR A, ROMÉRO MA, BRUNA GC, editores. Curso de gestão ambiental. Barueri: Manole; 2004. p.945-968.

SOUSA MLF, TAVARES LBB. A incompatibilidade entre a capacidade da natureza e o paradigma materialista da sociedade atual. Revista de Estudos Ambientais. 2013; v.15, n.2, p.58-67.

TÔSTO SG, RODRIGUES CAG, BOLFE EL, BATISTELLA M, editores. Geotecnologias e Geoinformação: o produtor pergunta, a Embrapa responde. Brasília: Embrapa; 2014. 248p.

VIEIRA A. O património geomorfológico no contexto da valorização da geodiversidade: sua evolução recente, conceitos e aplicação. Cosmos. 2014; v.7, n.1, p.28-59.

WERNECK BR. Avaliação da Susceptibilidade à Degradação Ambiental da Bacia Hidrográfica do Rio Macaé com apoio do Geoprocessamento [dissertação]. Macaé: Curso de Engenharia Ambiental/IFF; 2010. 92p.

XAVIER-DA-SILVA J. O que é geoprocessamento? Revista do CREA-RJ. 2009; n.79, p.42-44.

\section{AGRADECIMENTOS}


Ao IFFluminense e ao Programa de Pós-Graduação em Engenharia Ambiental (PPEA), pelo apoio institucional.

Recebido em: 15/08/2018

Aceite para publicação em: 05/11/2018 